\title{
Near-IR photodissociation of peroxy acetyl nitrate
}

\author{
S. A. Nizkorodov ${ }^{1}$, J. D. Crounse ${ }^{2}$, J. L. Fry ${ }^{2}$, C. M. Roehl ${ }^{3}$, and P. O. Wennberg ${ }^{3}$ \\ ${ }^{1}$ Department of Chemistry, University of California at Irvine, Irvine, CA 92697, USA \\ ${ }^{2}$ Division of Chemistry and Chemical Engineering, California Institute of Technology, Pasadena, CA 91125, USA \\ ${ }^{3}$ Division of Geological and Planetary Sciences and Division of Engineering and Applied Science, California Institute of \\ Technology, Pasadena, CA, 91125, USA
}

Received: 4 February 2004 - Published in Atmos. Chem. Phys. Discuss.: 1 March 2004

Revised: 28 April 2004 - Accepted: 7 May 2004 - Published: 10 February 2005

\begin{abstract}
Measurements of the $\mathrm{C}-\mathrm{H}$ overtone transition strengths combined with estimates of the photodissociation cross sections for these transitions suggest that near-IR photodissociation of peroxy acetyl nitrate (PAN) is less significant ( $J_{\text {near-IR }} \approx 3 \times 10^{-8} \mathrm{~s}^{-1}$ at noon) in the lower atmosphere than competing sinks resulting from unimolecular decomposition and ultraviolet photolysis. This is in contrast to the photochemical behavior of a related peroxy nitrate, pernitric acid (PNA), that undergoes rapid near-IR photolysis in the atmosphere with $J_{\text {near-IR }} \approx 10^{-5} \mathrm{~s}^{-1}$ at noon (Roehl et al., 2002). This difference is attributed to the larger binding energy and larger number of vibrational degrees of freedom in PAN, which make $4 v_{\mathrm{CH}}$ the lowest overtone excitation with a high photodissociation yield (as opposed to $2 v_{\mathrm{OH}}$ in PNA).
\end{abstract}

\section{Introduction}

Atmospheric photochemistry is normally driven by electronic state excitations in the ultraviolet range of the solar spectrum. However, photodissociation processes resulting from near-IR direct overtone excitations within the ground electronic state can also be significant in special cases (Donaldson et al., 2003). Donaldson et al. (1997) examined several atmospheric molecules featuring small binding energies and strong overtone transitions, and identified $\mathrm{HO}_{2} \mathrm{NO}_{2}$ (pernitric acid or PNA) as the most likely candidate for an efficient overtone photodissociation. They argued that the dissociation energy threshold for PNA, $\mathrm{D}_{0}\left(\mathrm{HO}_{2}\right.$ $\left.\mathrm{NO}_{2}\right)=7970 \pm 280 \mathrm{~cm}^{-1}$ (Zabel, 1995), is sufficiently low to permit its overtone photolysis via the second $\mathrm{OH}$ stretching overtone transition at $\mathrm{E}\left(3 \mathrm{v}_{\mathrm{OH}}\right)=10090 \mathrm{~cm}^{-1}$. Subsequent experimental study of near-IR photodissociation cross sections of PNA by Roehl et al. (2002) showed that PNA over-

Correspondence to: S. A. Nizkorodov

(nizkorod@uci.edu) tone dissociation is even more important than Donaldson et al. (1997) initially surmised. Roehl et al. (2002) found that PNA can photolyze with a substantial yield not only upon $3 v_{\mathrm{OH}}$ but also upon $2 v_{\mathrm{OH}}$ excitation at $6900 \mathrm{~cm}^{-1}$, which lies as much as $1070 \mathrm{~cm}^{-1}$ below the PNA formal dissociation energy threshold. These striking results have recently been independently confirmed by Sinha's research group (Matthews et al., 2004). Such efficient under-threshold photolysis can be attributed to the collisional activation and internal energy contributions to the dissociation process, just as in the well-known cases of ultraviolet photodissociation of $\mathrm{NO}_{2}$ (Pitts et al., 1964; Roehl et al., 1994) and $\mathrm{O}_{3}$ (FinlaysonPitts and Pitts, 2000), and overtone dissociation of nitric acid (Sinha et al., 1990). The combined $2 v_{\mathrm{OH}}$ and $3 v_{\mathrm{OH}}$ PNA atmospheric photodissociation rate amounts to $\approx 10^{-5} \mathrm{~s}^{-1}$, making near-IR photolysis the dominant sink process for PNA in the upper troposphere and lower stratosphere (Roehl et al., 2002).

This letter examines possible atmospheric significance of near-IR photolysis for another important peroxy nitrate, $\mathrm{CH}_{3} \mathrm{C}(\mathrm{O}) \mathrm{OONO}_{2}$ (peroxy acetyl nitrate or PAN). PAN is a key odd-nitrogen component of photochemical smog (Finlayson-Pitts and Pitts, 2000), and it serves both as a temporary reservoir and as a global transporter for $\mathrm{NO}_{\mathrm{x}}$. PAN often accounts for the largest fraction of all odd-nitrogen compounds $\left(\mathrm{NO}_{\mathrm{y}}\right)$ in the atmosphere, especially at high latitudes (Ridley et al., 2003; Stroud et al., 2003). The primary known sinks for PAN include unimolecular decomposition, which is the dominant channel in the lower atmosphere, and ultraviolet photolysis, which becomes prevalent in the colder upper tropospheric layers. Reaction of PAN with $\mathrm{OH}$ is too slow to be of relevance (DeMore et al., 1997). Similar to other peroxy nitrates (Kirchner et al., 1999; Zabel, 1995), PAN has a low dissociation energy, $\mathrm{D}_{0}\left(\mathrm{CH}_{3} \mathrm{C}(\mathrm{O}) \mathrm{OO}-\right.$ $\left.\mathrm{NO}_{2}\right)=9820 \pm 240 \mathrm{~cm}^{-1}$ (Bridier et al., 1991; Zabel, 1995), which falls between the $3 v_{\mathrm{CH}}\left(\mathrm{E} \approx 8550 \mathrm{~cm}^{-1}\right)$ and $4 v_{\mathrm{CH}}$ $\left(\mathrm{E} \approx 11100 \mathrm{~cm}^{-1}\right)$ vibrational states of the molecule. To

(C) 2005 Author(s). This work is licensed under a Creative Commons License. 
evaluate the efficiency of near-IR photochemistry of PAN, knowledge of both the intensity of the $\mathrm{CH}$ stretching overtones and photodisssociation quantum yields are required. Although the strength of $\mathrm{CH}$ stretching overtone transitions are well-known for many hydrocarbons (Hanazaki et al., 1985; Kjaergaard et al., 1991; Nakagaki and Hanazaki, 1986), no information on the cross sections and photodissociation quantum yields for PAN is presently available. In what follows, we show that these quantities can be estimated from statistical models and comparisons with experimental data on related molecules, and we use them to predict the near-IR photodissociation rates for PAN under typical atmospheric conditions.

\section{Results and discussion}

\subsection{Definitons and units}

Subject to the approximations described below, band-specific atmospheric photodissociation rates, $J_{\text {band }}$, can be calculated in the following way:

$$
J_{\text {band }}=\int_{\text {band }} F(\bar{v}) \sigma(\bar{v}) \phi(\bar{v}) d \bar{v} \approx\langle F(\bar{v})\rangle \times S_{\text {band }} \times \phi_{\text {band }}
$$

$F(\bar{v})$ is the frequency-dependent solar flux measured in $\frac{\text { photons }}{\mathrm{cm}^{2} \mathrm{scm}^{-1}},\langle F(\bar{v})\rangle$ is the average value of $F(\bar{v})$ over the absorption band, $\sigma(\bar{v})$ is base-e molecular absorption cross section in $\mathrm{cm}^{2} /$ molecule, $\phi(\bar{v})$ is photodissociation quantum yield, $\bar{v}$ is wave number in $\mathrm{cm}^{-1}$, and $S_{\text {band }}=\int_{\text {band }} \sigma(\bar{v}) d \bar{v}$ is the integrated absorption cross section (in $\mathrm{cm} /$ molecule) for the band in question. The last equality applies only if $F(\bar{v})$ varies weakly with frequency, which is usually a good approximation for the narrow near-IR bands unless they are close to strong water or carbon dioxide absorptions. The quantity $\phi_{\text {band }}$ is best interpreted as the ratio between the integrated photodissociation and absorption cross sections for the band. The paragraphs below deal with estimation of $S$ and $\phi$ for the $\mathrm{CH}$ stretching overtone transitions of PAN.

\subsection{PAN overtone absorption cross-sections}

Integrated absorption cross sections for PAN fundamentals have been reported by Gaffney et al. (1984). However, their analysis has subsequently been questioned and corrected by Tsalkani and Toupance (1989) for the four strongest infrared bands of PAN below $2000 \mathrm{~cm}^{-1}$. To resolve the resulting ambiguity of the intensity data for the remaining bands not considered by Tsalkani and Toupance (1989), we have measured relative intensities of the $\mathrm{CH}$ stretching fundamental and overtone transitions and determined absolute transition intensities by relation to Tsalkani and Toupance (1989) data for NO stretching vibrations of PAN. Pure gaseous PAN samples were synthesized as described by Gaffney et al. (1984), and gas-phase spectra of PAN were recorded with an FTIR spectrometer at $1 \mathrm{~cm}^{-1}$ resolution (Fig. 1). Depending on the examined spectral range, we used either a single-pass $20 \mathrm{~cm}$ cell containing 0.1-1 Torr partial pressure of PAN, or a multipass cell with an effective path length of $360 \mathrm{~cm}$ containing the equilibrium vapor pressure of PAN at room temperature (about 4.5 Torr). The multipass configuration was required to observe the second $\mathrm{CH}$ stretching overtone with an acceptable signal-to-noise ratio (Fig. 1).

The ratios of PAN band strengths were obtained from multiple spectra. The absorbances $(\mathrm{A}=\sigma(\bar{v}) \times[\mathrm{PAN}] \times$ pathlength $)$ for the bands in question were always kept small to avoid deviations from the Beer-Lambert law. For very weak transitions like $\mathrm{CH}-$ overtones there is no reason to believe that their integrated absorbances should deviate from a linear dependence on PAN concentration. For the stronger fundamental transitions, deviations from linearity are certainly possible, but we measured the ratio of the integrated absorbances at multiple partial pressures of PAN and always obtained the same result. This is an indirect proof that Beer-Lambert law was obeyed for these transitions under our experimental conditions. The value of $S\left(v_{\mathrm{CH}}\right)$ was measured relative to the band strengths of $\mathrm{NO}_{2}$ stretches reported by Tsalkani and Toupance (1989). Our value, $S\left(v_{\mathrm{CH}}\right)=1.57 \times 10^{-18} \mathrm{~cm} / \mathrm{molecule}$, is $40 \%$ lower than that reported by Gaffney et al. (1984). This agrees with the conclusions of Tsalkani and Toupance (1989), who showed that data from Gaffney et al. (1984) overestimated band intensities of PAN by 5 to 35\%. The $\mathrm{CH}$ stretching overtone band strengths were always measured relative to the closest available $\mathrm{CH}$ stretching transition at lower frequency. Our results $S\left(2 v_{\mathrm{CH}}\right) / S\left(v_{\mathrm{CH}}\right)=0.096 \pm 0.015$ and $S\left(3 v_{\mathrm{CH}}\right) / S\left(2 v_{\mathrm{CH}}\right)=0.085 \pm 0.030$ are consistent with the generally observed trend of the 10-fold drop of overtone intensity per vibrational quantum (we define $S\left(2 v_{\mathrm{CH}}\right)$ and $S\left(3 v_{\mathrm{CH}}\right)$ as the total integrated absorption cross section for the $5600-6300 \mathrm{~cm}^{-1}$ and $8300-9000 \mathrm{~cm}^{-1}$ ranges, respectively).

Integrated intensity for the $4 v_{\mathrm{CH}}$ overtone of PAN could not be reliably determined from our FTIR spectra, but it can be deduced from comparison with spectra of other molecules bearing an acetyl group. Indeed, the observed spectra of the first and second $\mathrm{CH}$ overtones of PAN (Fig. 1) closely resemble the spectra of acetone and acetaldehyde (Hanazaki et al., 1985). The orientational site splitting pattern arising from the inequivalence of $\mathrm{CH}$ bonds in the methyl group (Hanazaki et al., 1985; Kjaergaard et al., 1991) is similar for all three molecules. The integrated intensities (per methyl group) for the $v_{\mathrm{CH}}$ fundamental, $2 v_{\mathrm{CH}}$ first overtone, and $3 v_{\mathrm{CH}}$ second overtone bands are also quite similar (Table 1). Assuming that the PAN overtone intensity decreases with vibrational quantum number by the same factors as the average of the corresponding acetone and acetaldehyde values, $\mathrm{S}\left(4 v_{\mathrm{CH}}\right) / \mathrm{S}\left(3 v_{\mathrm{CH}}\right)=0.059$, we can estimate $S_{P A N}\left(4 v_{\mathrm{CH}}\right)$ as $7.6 \times 10^{-22} \mathrm{~cm} / \mathrm{molecule}$. Based on the good uniformity of 


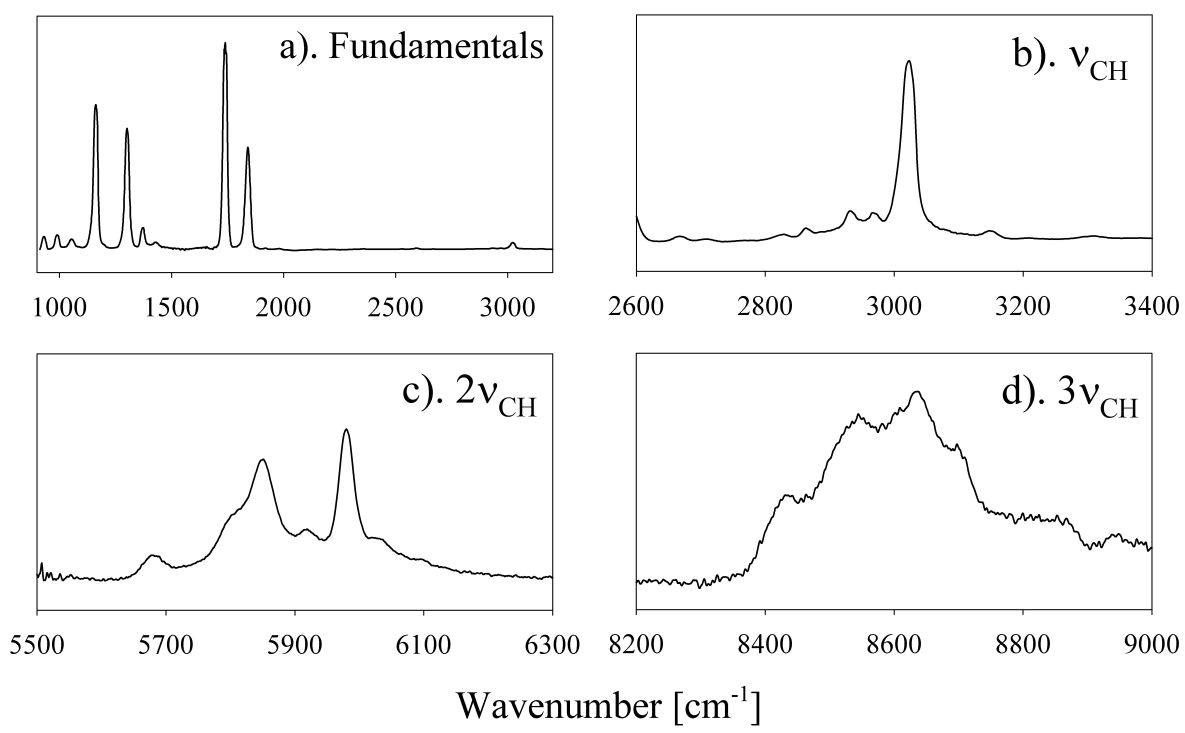

Fig. 1. IR spectrum of PAN recorded in this work: (a) fundamental range displaying well-known PAN bands; (b) $\mathrm{CH}$ stretching fundamental range; (c) first $\mathrm{CH}$ stretching overtone range; d) second $\mathrm{CH}$ stretching overtone range. The $\mathrm{CH}$-stretching overtones have a complicated band structure resulting from the inequivalence of $\mathrm{CH}$ bonds in the methyl group. Experimentally measured ratios between integrated absorption cross sections are $S\left(v_{\mathrm{CH}}\right): S\left(2 v_{\mathrm{CH}}\right): S\left(3 v_{\mathrm{CH}}\right)=1: 0.096: 0.0082 . S\left(v_{\mathrm{CH}}\right)$ is measured to be $1.57 \times 10^{-18} \mathrm{~cm} / \mathrm{molecule}$ (base $e$ ) in this work.

the experimentally available band strength ratios for these three molecules, we do not expect the estimated value of $S_{P A N}\left(4 v_{\mathrm{CH}}\right)$ to deviate from the true band strength by more than a factor of two.

\subsection{Photodissociation quantum yields}

Photodissociation quantum yields for $\mathrm{CH}$ overtone excitations of PAN have been calculated with the Multiwell suite (Barker, 2001) using a statistical approach. The calculation involves shifting the Boltzmann internal energy distribution of the molecule upward by the photon energy, and solving the coupled master equations for discretized internal energy states. Excited molecules can undergo either a unimolecular decomposition with the microcanonical rate constant $\mathrm{k}_{\text {uni }}(\mathrm{E})$ or collision-induced internal energy change with the rate that depends on pressure and internal energy. The fraction of molecules that end up decomposing by the time internal energy in the surviving molecules is nearly thermalized $\left(\approx 10^{3}\right.$ collisions) is taken as the photodissociation yield.

The quantum yield calculation presented here is based on the assumptions that: i) the internal energy can exchange freely between different vibrational degrees of freedom (Krotor states are also counted towards the total available energy); ii). The transition strengths for sequence (hot) bands originating from the low- frequency vibrational states and building upon $\mathrm{CH}$ overtones are the same as for the corresponding overtones themselves. The high frequency $\mathrm{CH}$ vibrations are known to couple quite weakly with the lowfrequency vibrational modes. Therefore, the second assumption is likely to hold, whereas the first one may in princi-
Table 1. Experimental integrated absorption cross sections (base $e$ ) for the $\mathrm{CH}$-stretching overtones of acetone, acetaldehyde, and PAN. The units of $S$ (band) are $\mathrm{cm}^{2} /$ molecule $\mathrm{cm}^{-1}\left(1 \mathrm{~cm}^{-2} \mathrm{~atm}^{-1}\right.$ at $298 \mathrm{~K}=4.063 \times 10^{-20} \mathrm{~cm} /$ molecule). The integrated absorption cross sections are given per $\mathrm{CH}_{3}$ group; i.e. the acetone values have been divided by 2 .

\begin{tabular}{crcc}
\hline Band & Acetone $/ 2^{a}$ & Acetaldehyde $^{a}$ & PAN \\
\hline$\left(v_{\mathrm{CH}}\right)$ & $3.04 \mathrm{E}-18$ & $2.02 \mathrm{E}-18$ & $1.57 \mathrm{E}-18$ \\
$2\left(v_{\mathrm{CH}}\right)$ & $1.28 \mathrm{E}-19$ & $1.51 \mathrm{E}-19$ & $1.51 \mathrm{E}-19^{b}$ \\
$3\left(v_{\mathrm{CH}}\right)$ & $1.60 \mathrm{E}-20$ & $1.63 \mathrm{E}-20$ & $1.28 \mathrm{E}-20^{c}$ \\
$4\left(v_{\mathrm{CH}}\right)$ & $1.09 \mathrm{E}-21$ & $8.21 \mathrm{E}-22$ & $7.56 \mathrm{E}-22^{d}$ \\
\hline
\end{tabular}

${ }^{a}$ From Hanazaki et al. (1985).

${ }^{b}$ Measured to be $9.6 \%$ of $S\left(v_{\mathrm{CH}}\right)$ in this work.

${ }^{c}$ Measured to be $8.5 \%$ of $S\left(2 v_{\mathrm{CH}}\right)$ in this work.

$d$ Assumed value based on comparison with acetone and acetaldehyde $\left(5.9 \%\right.$ of $\left.\mathrm{S}\left(3 v_{\mathrm{CH}}\right)\right)$.

ple break down leading to non-statistically long lifetimes of the vibrationally excited molecules. At finite pressures, the dissociation quantum yield may be reduced by these nonstatistical effects. The yields we are predicting will therefore represent an upper limit to the actual photodissociation yields.

The exponential collision model built into the Multiwell was used, with the probability of downward collisions taken as $e^{\left(E_{\text {final }}-E_{\text {initial }}\right) / \Delta}$, where $\Delta=45 \mathrm{~cm}^{-1}+0.005 \times E_{\text {initial }}$, a weak collision model (Barker, 2001). Vibrational 


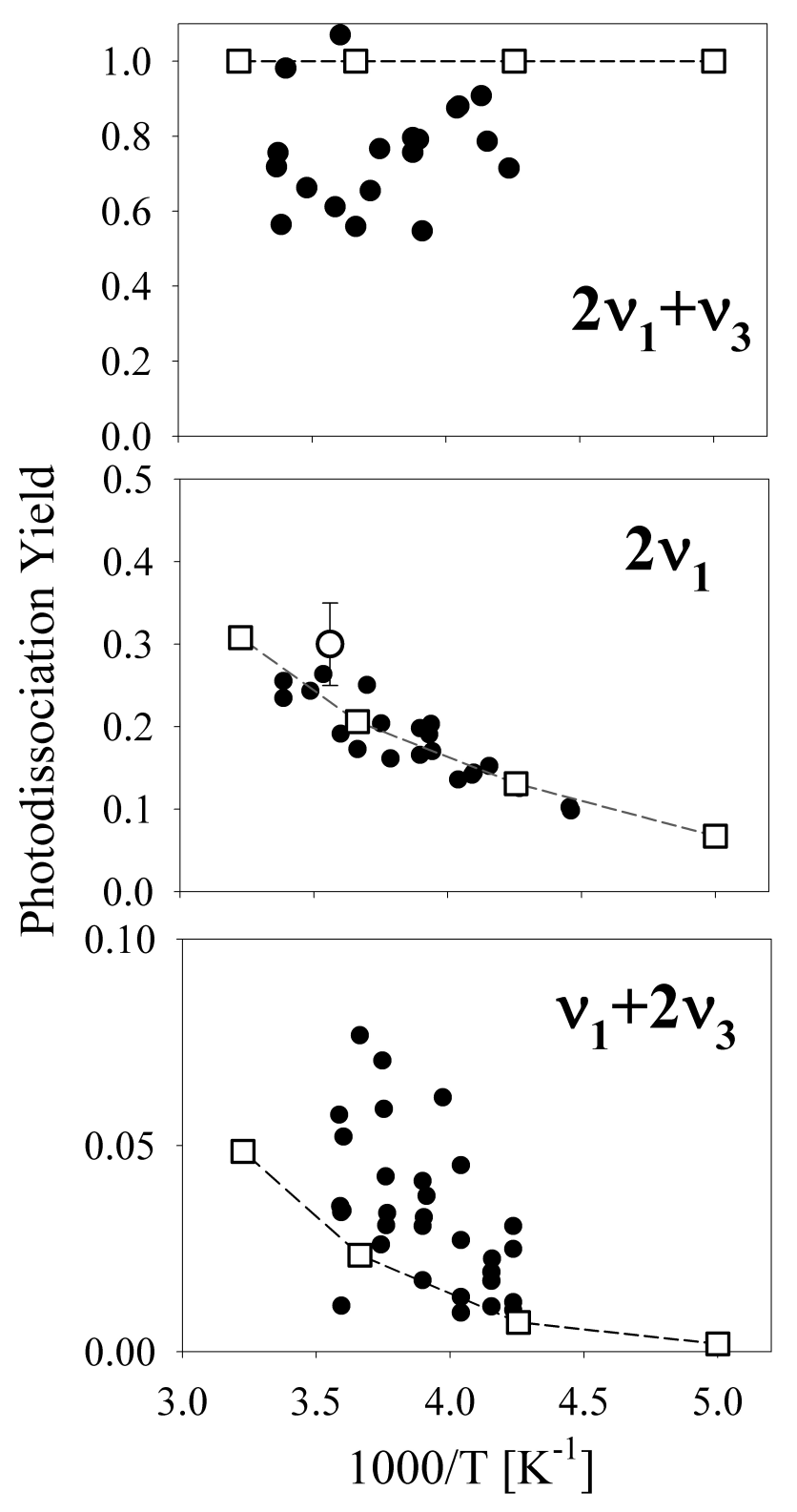

Fig. 2. Experimental photodissociation quantum yields for different vibrational overtone excitations of PNA measured by Roehl et al. (2002) (filled circles) compared to the statistical simulation results (open squares) of this work. Both simulations and data correspond to $\mathrm{P}=5$ Torr. The open circle point in the $2 v_{1}$ panel comes from Matthews et al. (2004) and it corresponds to $\mathrm{T}=298 \mathrm{~K}$, $\mathrm{P}=0.1$ Torr. Parameters for our statistical simulation were chosen to reproduce the $2 v_{1}$ photodissociation yields.

frequencies for PAN were taken from Miller et al. (1999). Lennard-Jones collision parameters were the same as used by Bridier et al. (1991). The $\mathrm{NO}_{2}$ and -C-O-O moieties were treated as hindered rotors in the transition state. The $\mathrm{CH}_{3}$ group was treated as a free rotor for both reactant and transition state. The initially-selected RRKM parameters were fine-tuned to reproduce i) high pressure limit of the experi- mental unimolecular decomposition rate (Bridier et al., 1991; Zabel, 1995); ii) the equilibrium constant for PAN decomposition (Bridier et al., 1991) at all experimentally available temperatures. The final choice of parameters for the calculation could reproduce both experimental data sets within $30 \%$.

The predictive power of the calculation was first tested on PNA because photodissociation quantum yields have already been measured for this molecule (Roehl et al., 2002). Figure 2 compares the experimental results with our statistical calculations for the $v_{\mathrm{OH}}+2 v_{\mathrm{OOH}}$ combination band, $2 v_{\mathrm{OH}}$ overtone, and $2 v_{\mathrm{OH}}+v_{\mathrm{OOH}}$ combination band of PNA (listed here in the order of increasing excitation energy). Required RRKM parameters for PNA were taken from experiment and from Chen and Hamilton (1996) and Zabel (1995). The simulation reproduces both the magnitude and the temperature dependence of the photodissociation quantum yields with good accuracy. To achieve this level of agreement, we had to reduce the dissociation energy threshold of PNA by $200 \mathrm{~cm}^{-1}$ from the accepted experimental value, which is well within the error bars for $\mathrm{D}_{0}\left(\mathrm{HO}_{2}-\right.$ $\left.\mathrm{NO}_{2}\right)=7970 \pm 280 \mathrm{~cm}^{-1}$ (Zabel, 1995). Staikova et al. (2002) also reported a lower dissociation energy for PNA.

A curious side result of this simulation is the prediction of unity quantum yield for the $2 v_{\mathrm{OH}}+v_{\mathrm{OOH}}$ excitation of PNA. The experimental data suggest a yield that is slightly below unity for this transition. This discrepancy may be a reflection of not entirely statistical behavior of PNA at these excitation energies. It may also reflect deficiencies of the chosen weak collision model. However, the experimental data for $2 v_{\mathrm{OH}}+v_{\mathrm{OOH}}$ and $v_{\mathrm{OH}}+2 v_{\mathrm{OOH}}$ bands are relatively noisy (Fig. 2) making it difficult to draw more definite conclusions. Matthews et al. (2004) assumed a photodissociation quantum yield of one for the $2 v_{\mathrm{OH}}+v_{\mathrm{OOH}}$ band in their work.

The predicted dissociation yields for PAN excitation at $8700 \mathrm{~cm}^{-1}$ (i.e. within the blue wing of the $3 v_{\mathrm{CH}}$ band) are shown in Fig. 3 for several atmospherically relevant temperatures. The most interesting observation is that the photodissociation yields for PAN display a remarkably broad pressure dependence. In contrast, the photodissociation yield for the $2 v_{\mathrm{OH}}$ overtone transition of PNA is fairly constant below $\mathrm{P}=1 \mathrm{~atm}$. This important difference can be attributed to the substantially larger number of vibrational degrees of freedom and larger binding energy in PAN resulting in lower microcanonical decomposition rates. The collisional deactivation and excitation rates can, therefore, easily compete with unimolecular decomposition even when the system is placed above the dissociation energy. In fact, the calculated PAN dissociation yields do not reach unity under typical atmospheric pressures even for excitation lying as much as $1000 \mathrm{~cm}^{-1}$ above the dissociation threshold (Fig. 4). In contrast, PNA is predicted to fall apart with $100 \%$ efficiency when excited so high above the dissociation energy threshold at pressures below one atmosphere. 
Table 2. Calculated photodissociation quantum yields for PAN overtone transitions under representative atmospheric conditions. The $J_{\text {near-IR }}$ column lists the total near-IR photodissociation rates $\left(J_{3 \nu \mathrm{CH}}+J_{4 v \mathrm{CH}}\right)$ calculated from the integrated absorption cross sections from Table 1 and a solar flux of $5 \times 10^{14}$ photons $\mathrm{cm}^{-2} \mathrm{~s}^{-1} \mathrm{~nm}^{-1}$. The last column is the fractional contribution of under-threshold dissociation via $3 v_{\mathrm{CH}}$ to the total rate (i.e. $J_{3 v \mathrm{CH}} / J_{\text {near}}-\mathrm{IR}$ ).

\begin{tabular}{ccccccc}
\hline $\begin{array}{c}\text { Altitude } \\
(\mathrm{km})\end{array}$ & $\begin{array}{c}\mathrm{T} \\
(\mathrm{K})\end{array}$ & $\begin{array}{c}\mathrm{P} \\
(\text { Torr })\end{array}$ & $\phi\left(3 v_{\mathrm{CH}}\right)$ & $\phi\left(4 v_{\mathrm{CH}}\right)$ & $\begin{array}{c}J_{\text {near }-\mathrm{IR}} \\
\left(\mathrm{s}^{-1}\right)\end{array}$ & $\begin{array}{c}3 v_{\mathrm{CH}} \text { contribution } \\
(\%)\end{array}$ \\
\hline 0 & 288 & 760 & 0.0041 & 0.80 & $2.8 \mathrm{E}-8$ & 14.8 \\
3 & 269 & 526 & 0.0027 & 0.82 & $2.8 \mathrm{E}-8$ & 9.3 \\
6 & 249 & 354 & 0.0016 & 0.85 & $2.7 \mathrm{E}-8$ & 5.5 \\
9 & 230 & 230 & 0.0009 & 0.88 & $2.8 \mathrm{E}-8$ & 3.0 \\
12 & 217 & 143 & 0.0007 & 0.92 & $2.9 \mathrm{E}-8$ & 2.2 \\
15 & 217 & 90 & 0.0011 & 0.97 & $3.1 \mathrm{E}-8$ & 3.1 \\
\hline
\end{tabular}

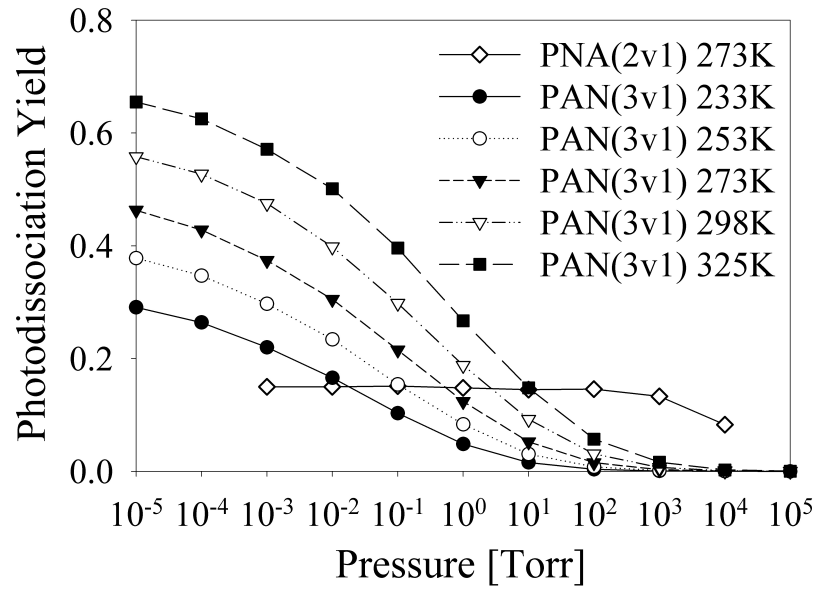

Fig. 3. Pressure dependence of the predicted photodissociation quantum yields for $8700 \mathrm{~cm}^{-1}$ excitation of PAN (representative of the $3 v_{\mathrm{CH}}$ excitation) at different temperatures. Calculated photodissociation yields for $2 v_{\mathrm{OH}}$ band of PNA at $273 \mathrm{~K}$ are also shown for comparison. In contrast to the PNA case, photodissociation quantum yields for PAN photolysis at $8700 \mathrm{~cm}^{-1}$ strongly depend on pressure under typical atmospheric conditions.

\section{4 near-IR photodissociation rates for atmospheric PAN}

Simulated PAN photodissociation yields for a standardized atmosphere are given in Table 2. The effective photodissociation yield for $3 v_{\mathrm{CH}}$ band (estimated as an average of yields calculated for 8450,8550 , and $8650 \mathrm{~cm}^{-1}$ excitations) is very small compared to the $4 v_{\mathrm{CH}}$ yield (corresponding to $11100 \mathrm{~cm}^{-1}$ excitation). Using the transition strength data from Table 1 and a typical near-IR solar flux of $5 \times 10^{14}$ photons $\mathrm{cm}^{-2} \mathrm{~s}^{-1} \mathrm{~nm}^{-1}$ (Finlayson-Pitts and Pitts, 2000), we estimate the total near-IR photodissociation rate for PAN as $J_{\text {near-IR }} \approx 3 \times 10^{-8} \mathrm{~s}^{-1}$ with a fairly weak altitude dependence (Table 2).

Because of the very low contribution of the $3 v_{\mathrm{CH}}$ band of PAN to the total near-IR photolysis rate $(<5 \%$ above $6 \mathrm{~km})$,

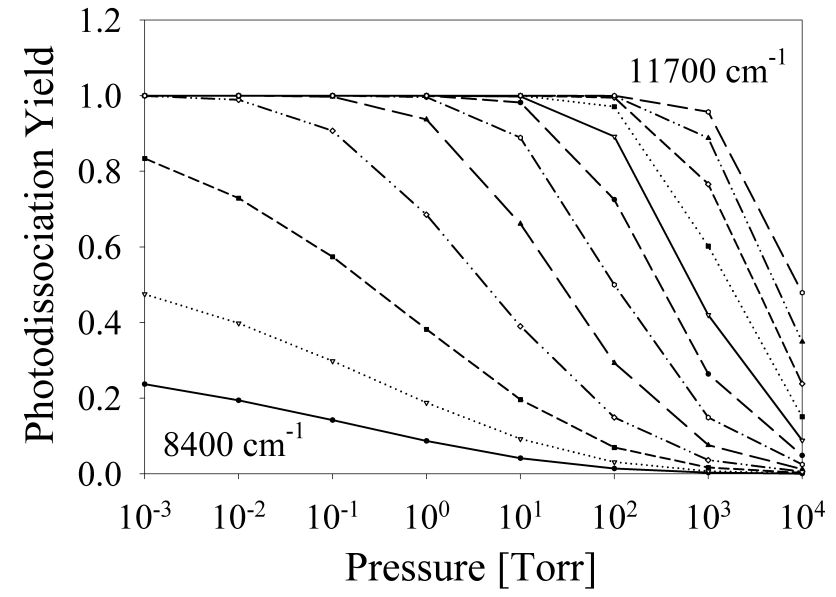

Fig. 4. Pressure dependence of the predicted photodissociation quantum yields of PAN at $298 \mathrm{~K}$ at different excitation frequencies. The frequencies cover the range $8400 \mathrm{~cm}^{-1}$ (bottom curve) to $11700 \mathrm{~cm}^{-1}$ (top curve) in $300 \mathrm{~cm}^{-1}$ increments. Even at the highest excitation energy, the yield is still noticeably different from unity at typical atmospheric pressures.

the predicted rate is relatively insensitive to the calculated photodissociation yields. For example, an order of magnitude increase in $\phi\left(3 v_{\mathrm{CH}}\right)$ would translate to less than $50 \%$ increase in the total photolysis rate. The $\phi\left(4 v_{\mathrm{CH}}\right)$ values are already above 0.8; adjusting them to the maximal value of unity would only produce a marginal increase in the rate. The confidence in the predicted rate is, therefore, dominated by the uncertainty in $S\left(4 v_{\mathrm{CH}}\right)$ believed to be accurate to within a factor of two (Table 1). Given these uncertainties, a very conservative upper limit for the near-IR PAN photodissociation rate under typical atmospheric conditions can be set at $J_{\text {near-IR }}(\mathrm{PAN})<10^{-7} \mathrm{~s}^{-1}$. Using similar reasoning, one can also show that $J_{\text {near }-I R}$ is insensitive to poor atmospheric transmittance at wavelengths corresponding to $3 v_{\mathrm{CH}}$ transition (the $4 v_{\mathrm{CH}}$ spectral range is clean). 


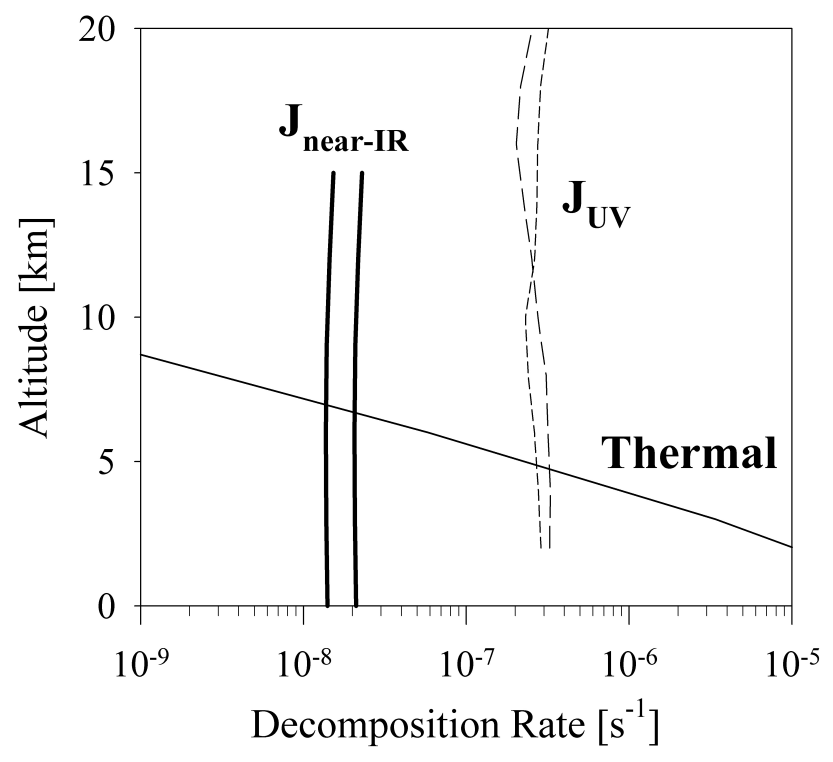

Fig. 5. Dependence of the predicted 24 hour-averaged near IR photodissociation rates (thick solid lines), UV photolysis rates (dashed lines), and unimolecular decomposition rate (thin solid line) on altitude. The UV photolysis rates were calculated for actual conditions of 8 May, $67^{\circ} \mathrm{N}$ (short dash) and 25 September, $35^{\circ} \mathrm{N}$ (long dash). Two near IR photolysis curves correspond to 18 -hour (8 May) and 12-hour (25 September) day lengths with an average solar flux of $5 \times 10^{14}$ photons $\mathrm{cm}^{-2} \mathrm{~s}^{-1} \mathrm{~nm}^{-1}$. The near IR channel is seen to play a minor role $(<10 \%)$ at all altitudes.

This limit is to be contrasted with a characteristic nearIR photolysis rate for PNA, $J_{\text {near-IR }}(\mathrm{PNA}) \approx 10^{-5} \mathrm{~s}^{-1}$, which is higher by two orders of magnitude. The large difference in the photodissociation rates for PAN and PNA reflects the disparity in absorption cross sections for the overtone excitations responsible for their near-IR photodissociation activity. Whereas the under-threshold $2 v_{\mathrm{OH}}$ excitation accounts for the major fraction of $J_{\text {near-IR }}(\mathrm{PNA})$, the $3 v_{\mathrm{CH}}$ band of PAN is but a minor contributor $(<5 \%$ above $6 \mathrm{~km})$ to $J_{\text {near-IR }}(\mathrm{PAN})$. Because the overtone absorption strengths go down by roughly one order of magnitude with each vibrational quantum, the jump in two vibrational quanta between the primary photolytic excitations in $\operatorname{PAN}\left(4 v_{\mathrm{CH}}\right)$ and $\mathrm{PNA}\left(2 v_{\mathrm{OH}}\right)$ can be held responsible for the observed difference in the $J_{\text {near-IR }}$ values. In addition, $\mathrm{CH}_{3}$ overtone intensities in acetyl groups are known to be systematically lower than those of other kinds of $\mathrm{CH}_{3}$ groups (Nakagaki and Hanazaki, 1986). They are also considerably lower than intensities of typical $\mathrm{OH}$ stretching overtones (e.g. compare $S_{\mathrm{PNA}}\left(2 v_{\mathrm{OH}}\right)=(9.5 \pm 1.9) \times 10^{-19} \mathrm{~cm} / \#$ (Roehl et al., 2002) with $\left.S_{\text {PAN }}\left(2 v_{\mathrm{CH}}\right)=1.51 \times 10^{-19} \mathrm{~cm} / \#\right)$.

Although the predicted near-IR photodissociation rate of PAN is quite low (the 24-h average of $1.5 \times 10^{-8} \mathrm{~s}^{-1}$ translates into an atmospheric lifetime of 770 days), it becomes strongly competitive with the thermal decomposition rate
(Zabel, 1995) above $6 \mathrm{~km}$ (Table 2 and Fig. 5). It is also higher than the upper limit for the rate of $\mathrm{OH}+\mathrm{PAN}$ reaction $\left(\mathrm{k}_{\mathrm{OH}+\mathrm{PAN}}[\mathrm{OH}]<10^{-8} \mathrm{~s}^{-1}\right.$ for the troposphere; DeMore et al., 1997). Comparison with the UV photolysis rate of PAN is less straightforward because UV radiation is attenuated by the atmosphere to a much greater extent than near-IR at high solar zenith angle (SZA). For example, at $15 \mathrm{~km}$ altitude, $J_{U V}(\mathrm{PAN}) \approx 6 \times 10^{-7} \mathrm{~s}^{-1}$ at $\mathrm{SZA}=0^{\circ}$ but it drops to $\approx 6 \times 10^{-8} \mathrm{~s}^{-1}$ at $\mathrm{SZA}=86^{\circ}$ (solar fluxes for this calculation are taken from Finlayson-Pitts and Pitts, 2000 and PAN absorption cross sections are from DeMore et al., 1997). On the contrary, the estimated near-IR photolysis rate $\left(\approx 3 \times 10^{-8} \mathrm{~s}^{-1}\right)$ is reduced by only $35 \%$ upon this SZA change. Consequently, the near-IR photolysis of PAN can potentially become comparable to the UV photolysis rate at very high SZA, providing a small contribution to the twilight production of $\mathrm{HO}_{\mathrm{x}}$ radicals at high altitudes (Wennberg et al., 1999).

Figure 5 displays 24-hour averaged rates of UV photolysis, near-IR photolysis, and thermal decomposition for PAN. The UV photolysis rates correspond to conditions found at high and middle latitudes near equinox as described in Salawitch et al. (2002) (8 May 1997 with latitudes between $65^{\circ} \mathrm{N}$ and $70^{\circ} \mathrm{N}$ and 25 September 1993 at $35^{\circ} \mathrm{N}$ ). NearIR rates are estimated by assuming day lengths of $18 \mathrm{~h}$ and $12 \mathrm{~h}$, respectively, and a near-IR solar flux of $5 \times 10^{14}$ photons $\mathrm{cm}^{-2} \mathrm{~s}^{-1} \mathrm{~nm}^{-1}$. The thermal decomposition rate for PAN is calculated from data of Zabel (1995). Figure 5 shows that $<J_{\text {near }- \text { IR }}(\mathrm{PAN})>$ is approximately $5-10 \%$ of $<J_{\mathrm{UV}}(\mathrm{PAN})>$ at high tropospheric altitudes. At lower altitudes, both photolysis channels are dwarfed by the thermal decomposition. We conclude that near-IR photolysis is not likely to significantly affect the average atmospheric lifetime of PAN. Given that it is hard to quantify the uncertainties of the predicted photodissociation yields and absorption cross sections of PAN, however, the near-IR photolysis of PAN in the atmosphere cannot be completely discounted at this stage. More experimental research in this area is clearly needed.

\subsection{Experiments on near-IR photolysis of PAN}

We have attempted to measure photodissociation cross sections of PAN in the $3 v_{\mathrm{CH}}-4 v_{\mathrm{CH}}$ range using the action spectroscopy approach similar to that used for PNA by Roehl et al. (2002). PAN/ $\mathrm{N}_{2}$ mixture at $1-5$ Torr and $250-300 \mathrm{~K}$ was irradiated with a tunable pulsed near-IR laser in the presence of a small amount of $\mathrm{NO}$ and $\mathrm{O}_{2}$. A dye laser was employed in a fluorescence scheme to monitor the $\mathrm{OH}$ produced in the mixture following the photolysis laser pulse. If the near-IR laser were to photolyze PAN molecules in the gas flow, a momentary increase in the $\mathrm{OH}$ fluorescence signal would be observed assuming that the following reaction sequence runs to completion:

$\mathrm{PAN}+\mathrm{h} v($ near-IR $) \rightarrow \mathrm{CH}_{3} \mathrm{C}(\mathrm{O}) \mathrm{O}_{2}+\mathrm{NO}_{2}$ 


$$
\begin{aligned}
& \mathrm{CH}_{3} \mathrm{C}(\mathrm{O}) \mathrm{O}_{2}+\mathrm{NO} \rightarrow \mathrm{CH}_{3}+\mathrm{CO}_{2}+\mathrm{NO}_{2} \\
& \mathrm{CH}_{3}+\mathrm{O}_{2} \rightarrow \mathrm{CH}_{3} \mathrm{O}_{2} \\
& \mathrm{CH}_{3} \mathrm{O}_{2}+\mathrm{NO} \rightarrow \mathrm{CH}_{3} \mathrm{O}+\mathrm{NO}_{2} \\
& \mathrm{CH}_{3} \mathrm{O}+\mathrm{O}_{2} \rightarrow \mathrm{CH}_{2} \mathrm{O}+\mathrm{HO}_{2} \\
& \mathrm{HO}_{2}+\mathrm{NO} \rightarrow \mathrm{OH}+\mathrm{NO}_{2} .
\end{aligned}
$$

Despite numerous attempts under various reaction conditions, we have not been able to observe any near-IR laser induced increase in the $\mathrm{OH}$ signal. Detailed kinetic simulations of our experimental conditions predict a signal-to-noise ratio reduction of $\approx 10^{2}$ for $3 v_{\mathrm{CH}}$ band of PAN compared to $3 v_{\mathrm{OH}}$ band of PNA (which could be successfully observed in this apparatus, Roehl et al., 2002) assuming unity photodissociation yield in both cases. This large penalty is comprised of i) a factor of 2 reduction in the integrated absorption cross section; ii) factor of 5 increase in the effective band width for the $\mathrm{CH}_{3}$ vs. $\mathrm{OH}$ second overtone; iii) a factor of $\sim 10$ reduction in the efficiency of conversion of $\mathrm{CH}_{3} \mathrm{C}(\mathrm{O}) \mathrm{O}_{2}$ into $\mathrm{OH}$ in the chemical sequence above, as opposed to that of $\mathrm{HO}_{2}$ into $\mathrm{OH}$ in the case of PNA photodissociation. The signalto-noise ratio in our best $3 v_{\mathrm{OH}}$ photodissociation spectrum of PNA $\left(\approx 10^{3}\right.$, Roehl et al., 2002) allows us to place an upper limit of $10 \%$ on the photodissociation yield of the $3 v_{\mathrm{CH}}$ state of PAN at 1-5 Torr and $250-300 \mathrm{~K}$, which is in rough agreement with simulations presented here. The predicted signalto-noise ratio for the $4 v_{\mathrm{CH}}$ band of PAN is $<0.5$, consistent with the failure to experimentally detect it.

We are currently designing an experiment that will allow us to measure $\mathrm{CH}_{3} \mathrm{C}(\mathrm{O}) \mathrm{O}_{2}$ following pulsed near IR laser excitation of PAN $/ \mathrm{N}_{2}$ mixtures using a CIMS (chemical ionization mass spectrometry) technique. Preliminary tests show positive results using UV photons to dissociate PAN. The results of this work will be published elsewhere.

\section{Conclusions}

Due to its unique combination of binding energy and molecular size, PNA may well turn out to be the only peroxy nitrate that is controlled by near-IR photolysis (Roehl et al., 2002) in the atmosphere. The larger binding energies and higher degrees of molecular complexity make peroxy acetyl nitrates, like PAN, considerably more resistant to direct overtone photolysis in the near-IR range of the solar spectrum. Specifically, our analysis predicts a near-infrared photodissociation rate of $\approx 3 \times 10^{-8} \mathrm{~s}^{-1}$ for PAN at noon, largely independent of altitude. The near-IR photolysis of PAN can become competitive with UV photolysis under twilight illumination conditions, but even in the coldest upper tropospheric layers it is calculated to contribute only $5-10 \%$ to the 24-hour averaged removal rate of PAN.
Acknowledgements. This work was funded in part by NASA's Atmospheric Effects of Aviation Program and the Atmospheric Chemistry program of the National Science Foundation. SAN thanks the Camille and Henry Dreyfus Foundation for financial support during his postdoctoral research at Caltech. The authors thank R. Salawitch (JPL) for providing 24-averaged UV-photolysis rates of PAN used in Fig. 5 and A. Sinha (UCSD) for a preprint of Ref. (Matthews et al., 2004).

Edited by: J. Abbatt

\section{References}

Barker, J. R.: Multiple-well, multiple-path unimolecular reaction systems. I. Multiwell computer program suite, Int. J. Chem. Kinetics, 33, 232-245, 2001.

Bridier, I., Caralp, F., Loirat, H., Lesclaux, R., Veyret, B., Becker, K.H., Reimer, A. and Zabel, F.: Kinetic and theoretical studies of the reactions $\mathrm{CH}_{3} \mathrm{C}(\mathrm{O}) \mathrm{O}_{2}+\mathrm{NO}_{2}+\mathrm{M} \leftrightarrow \mathrm{CH}_{3} \mathrm{C}(\mathrm{O}) \mathrm{O}_{2} \mathrm{NO}_{2}+\mathrm{M}$ between $248 \mathrm{~K}$ and $393 \mathrm{~K}$ and between 30 Torr and 760 Torr, J. Phys. Chem., 95, 9, 3594-3600, 1991.

Chen, Z. and Hamilton, T. P.: Ab initio study of pernitric acid: comparison with experimental spectra, J. Phys. Chem., 100, 39, 15731-15 734, 1996.

DeMore, W. B., Sander, S. P., Golden, D. M., Hampson, R. F., Kurylo, M. J., Howard, C. J., Ravishankara, A. R., Kolb, C. E., and Molina, M. J.: Chemical kinetics and photochemical data for use in stratospheric modeling: Evaluation number 12. Jet Propulsion Laboratory, Pasadena, 1997.

Donaldson, D. J., Frost, G. J., Rosenlof, K. H., Tuck, A. F., and Vaida, V.: Atmospheric radical production by excitation of vibrational overtones via absorption of visible light, Geophys. Res. Lett., 24, 21, 2651-2654, 1997.

Donaldson, D.J., Tuck, A.F. and Vaida, V.: Atmospheric Photochemistry via vibrational overtone absorption, Chem. Rev., 103 , 12, 4717-4729, 2003.

Finlayson-Pitts, B. J. and Pitts, J. N.: Chemistry of the upper and lower atmosphere: theory, experiments, and applications, Academic Press, 1040, 2000.

Gaffney, J. S., Fajer, R., and Senum, G. I.: An improved procedure for high purity gaseous peroxyacyl nitrate production: use of heavy lipid solvents, Atmos. Environ., 18, 1, 215-18, 1984.

Hanazaki, I., Baba, M., and Nagashima, U.: Orientational site splitting of methyl C-H overtones in acetone and acetaldehyde, J. Phys. Chem., 89, 26, 5637-5645, 1985.

Kirchner, F., Mayer-Figge, A., Zabel, F., and Becker, K. H.: Thermal stability of peroxynitrates, Int. J. Chem. Kinetics, 31, 2, 127 144, 1999.

Kjaergaard, H. G., Henry, B. R., and Tarr, A. W.: Intensities in local mode overtone spectra of dimethyl ether and acetone, J. Chem. Phys., 94, 9, 5844-5854, 1991.

Matthews, J., Sharma, R., and Sinha, A.: Photodissociation of vibrationally excited pernitric acid: $\mathrm{HO}_{2} \mathrm{NO}_{2}\left(2 \mathrm{v}_{\mathrm{OH}}\right)+390 \mathrm{~nm}$, J. Phys. Chem. A, 108, 39, 8134-8139, 2004.

Miller, C. E., Lynton, J. I., Keevil, D. M., and Francisco, J. S.: Dissociation pathways of peroxyacetyl nitrate (PAN), J. Phys. Chem., 103, 51, 11 451-11 459, 1999.

Nakagaki, R. and Hanazaki, I.: Overtone spectroscopy of acetyl compounds. Inequivalent carbon-hydrogen $(\mathrm{CH})$ oscillators and 
substituent effects of the carbonyl group, Chem. Phys. Lett., 128, 4, 432-438, 1986.

Pitts Jr., J. N., Sharp, J. H., and Chan, S. I.: Effects of wavelength and temperature on primary processes in the photolysis of nitrogen dioxide and a spectroscopic-photochemical determination of the dissociation energy, J. Chem. Phys., 40, 12, 3655-3662, 1964.

Ridley, B. A., Atlas, E. L., Montzka, D. D., Browell, E. V., Cantrell, C. A., Blake, D. R., Blake, N. J., Cinquini, L., Coffey, M. T., Emmons, L. K., Cohen, R. C., DeYoung, R. J., Dibb, J. E., Eisele, F. L., Flocke, F. M., Fried, A., Grahek, F. E., Grant, W. B., Hair, J. W., Hannigan, J. W., Heikes, B. J., Lefer, B. L., Mauldin, R. L., Moody, J. L., Shetter, R. E., Snow, J. A., Talbot, R. W., Thornton, J. A., Walega, J. G., Weinheimer, A. J., Wert, B. P., and Wimmers, A. J.: Ozone depletion events observed in the high-latitude surface layer during the TOPSE aircraft program, J. Geophys. Res. D, 108, D4, TOP 4/1-TOP 4/22, 2003.

Roehl, C. M., Nizkorodov, S. A., Zhang, H., Blake, G. A., and Wennberg, P. O.: Photodissociation of peroxynitric acid in the near-IR, J. Phys. Chem. A, 106, 15, 3766-3772, 2002.

Roehl, C. M., Orlando, J. J., Tyndall, G. S., Shetter, R. E., Vazquez, G. J., Cantrell, C. A., and Calvert, J. G.: Temperature dependence of the quantum yields for the photolysis of $\mathrm{NO}_{2}$ near the dissociation limit, J. Phys. Chem., 98, 32, 7837-7843, 1994.
Salawitch, R. J., Wennberg, P. O., Toon, G. C., Sen, B., and Blavier, J.-F.: Near IR photolysis of $\mathrm{HO}_{2} \mathrm{NO}_{2}$ : implications for $\mathrm{HO}_{\mathrm{x}}$, Geophys. Res. Lett., 29, 16, 9/1-9/4, 2002.

Sinha, A., Vander Wal, R.L. and Crim, F.F.: State-resolved unimolecular reactions: the vibrational overtone initiated decomposition of nitric acid, J. Chem. Phys., 92, 1, 401-10, 1990.

Staikova, M., Donaldson, D.J. and Francisco, J.S.: Overtoneinduced reactions on the $\mathrm{HO}_{2} \mathrm{NO}_{2}$ potential surface, J. Phys. Chem. A, 106, 12, 3023-3028, 2002.

Stroud, C., Madronich, S., Atlas, E., Ridley, B., Flocke, F., Weinheimer, A., Talbot, B., Fried, A., Wert, B., Shetter, R., Lefer, B., Coffey, M., Heikes, B., and Blake, D.: Photochemistry in the arctic free troposphere: $\mathrm{NO}_{\mathrm{x}}$ budget and the role of odd nitrogen reservoir recycling, Atmos. Environ., 37, 24, 3351-3364, 2003.

Tsalkani, N. and Toupance, G.: Infrared absorptivities and integrated band intensities for gaseous peroxyacetyl nitrate (PAN), Atmos. Environ., 23, 8, 1849-1854, 1989.

Wennberg, P. O., Salawitch, R. J., Donaldson, D. J., Hanisco, T. F., Lanzendorf, E. J., Perkins, K. K., Lloyd, S. A., Vaida, V., Gao, R. S., Hintsa, E. J., Cohen, R. C., Swartz, W. H., Kusterer, T. L., and Anderson, D. E.: Twilight observations suggest unknown sources of $\mathrm{HO}_{\mathrm{x}}$, Geophys. Res. Lett., 26, 10, 1373-1376, 1999.

Zabel, F.: Unimolecular Decomposition of Peroxynitrates, Z. Phys. Chem., 188, 119-142, 1995. 